\title{
Helikobakter Pylori Birinci Basamak Tedavisi Alan Hastalarda Üç Farklı Tedavi Rejiminin Etkinliğinin Değerlendirilmesi
}

\section{Evaluation of the Effectiveness of Three Different Treatment Regimens in Patients Receiving Helicobacter Pylori First-Line Therapy}

\author{
$\underline{\text { Nazım EKIN } 1 \text { (D), }}$, Berat EBiK ${ }^{1}(\mathrm{D})$, Ferhat BACAKSIZ ${ }^{1}$ \\ ${ }^{1}$ Diyarbakır Sağlık Bilimleri Üniversitesi Gazi Yaşargil Eğitim ve Araştırma Hastanesi İç Hastalıkları Kliniği, Gastroenteroloji \\ Bölümü, Diyarbakır, TÜRKiYE
}

öz.

Amaç: Bu çalışmadaki amacımı en sık kullanılan Helikobakter pylori (Hp) tedavi rejimlerinin HP eradikasyon başarı oranlarını saptamaktır.

Materyal ve Metod: 2016 - 2020 yılları arasında üst gastrointestinal sistem endoskopisi sırasında Helikobakter pylori pozitif saptanan ve eradikasyon tedavisi sonrası kontrol endoskopik biyopsi alınan hastalar geriye dönük olarak değerlendirildi. Hastalar tedavi rejimlerine göre 3 gruba ayrıldı; lansoprazol $30 \mathrm{mg} \mathrm{2 \times 1}$, klaritromisin $500 \mathrm{mg} 2 \times 1$, amoksisilin $1000 \mathrm{mg} 2 \times 114$ gün alanlar (grup 1, n=20), lansoprazol $30 \mathrm{mg} 2 \times 1$, bizmut subsalisilat $262 \mathrm{mg} 4 \times 1$, klaritromisin $500 \mathrm{mg} \mathrm{2 \times 1}$, amoksisilin $1000 \mathrm{mg} 2 \times 114$ gün alanlar (grup 2, $n=23$ ) ve lansoprazol $30 \mathrm{mg} 2 \times 1$, bizmut subsalisilat $262 \mathrm{mg} 4 \times 1$, metronidazol $500 \mathrm{mg}$ $3 \times 1$, tetrasiklin $500 \mathrm{mg} 4 \times 114$ gün alanlar (grup 3, $n=17$ ). Bu üç grubun tedavi başarıları değerlendirildi. Bulgular: Çalışmaya, ortalama yaşı $42.8 \pm 15.17$ olan 60 hasta dahil edildi. Grup 1,2 ve 3 'ün yaş ortalamaları sırasıyla $40.05 \pm 15.33,42.86 \pm 15.90$ ve $46.23 \pm 14.14$ olup gruplar arasında istatiksel olarak anlamlı farklılık yoktu. Çalışmaya alınan hastaların \%57.6'sında (34/60) eradikasyon tedavisi sonrası Hp eradikasyonu sağlandı. Grup 1, 2 ve 3'teki HP eradikasyon oranları sırasıyla \%50, \%52.2 ve \%66.7 idi. Gruplar arasında başarı oranları açısından istatiksel olarak anlamlı farklılık yoktu.

Sonuç: Bu çalışmada, yüksek antibiyotik direnci ve hedeflenen eradikasyon oranlarından daha düşük eradikasyon oranları nedeniyle klasik üçlü tedavi, bizmut eklenmiş klasik üçlü tedavi ve bizmutlu dörtlü tedavinin Türkiye'de kullanılmasının uygun olmayabileceği sonucuna vardık. Helikobakter pylori tedavisinde yeni tedavi rejimlerinin geliştirilmesi gerekmektedir.

Anahtar kelimeler: Helikobakter pylori, Eradikasyon, Üçlü tedavi, Dörtlü tedavi

Abstract

Background: BI The aim of our study is to determine the Helicobacter pylori ( $\mathrm{Hp}$ ) eradication success rates of the most commonly used $\mathrm{Hp}$ treatment regimens.

Materials and Methods: Patients who diagnosed with Hp during upper gastrointestinal endoscopy and received control endoscopic biopsy after treatment between 2016 and 2020 were retrospectively evaluated. Patients were divided into three groups according to their treatment regimens: Group 1, lansoprazole $30 \mathrm{mg} 2 \times 1$, clarithromycin $500 \mathrm{mg} 2 \times 1$, amoxicillin $1000 \mathrm{mg} 2 \times 114$ days; Group 2, lansoprazole $30 \mathrm{mg} 2 \times 1$, bismuth subsalicylate $262 \mathrm{mg} 4 \times 1$, clarithromycin $500 \mathrm{mg} \mathrm{2 \times 1}$, amoxicillin 1000 mg 2x1 14 days; and Group 3, lansoprazole $30 \mathrm{mg} 2 \times 1$, bismuth subsalicylate $262 \mathrm{mg} 4 \times 1$, metronidazole $500 \mathrm{mg} 3 \times 1$, tetracycline $500 \mathrm{mg} 4 \times 114$ days. The success rates of three groups were evaluated. Results: Sixty patients with a mean age of $42.8 \pm 15.17$ years were included in the study. The mean age of groups 1,2 and 3 were $40.05 \pm 15.33,42.86 \pm 15.90$, and $46.23 \pm 14.14$, respectively, and there was no statistically significant difference among groups. Hp eradication was achieved in $57.6 \%(34 / 60)$ of the patients included in the study after eradication treatment. HP eradication rates in groups 1,2 and 3 were $50 \%, 52.2 \%$ and $66.7 \%$, respectively. There was no statistically significant difference among the groups in terms of success rates.

Conclusions: In this study, we concluded that classical triple therapy, classic triple treatment with added bismuth and quadruple therapy with bismuth may not be appropriate used in Turkey due to high antibiotic resistance and low eradication rates. New treatment regimens need to be developed to treat Helicobacter pylori.

Key Words: Helicobacter pylori, Eradication, Triple therapy, Quadruple therapy
Corresponding Author / Sorumlu Yazar

Dr. Nazım EKiN

Diyarbakır SBÜ Gazi Yaşargil Eğitim ve Araştırma Hastanesi Gastroenteroloji Kliniği, Diyarbakır/TüRKiYE

E-mail: ekinnzm@gmail.com

Received / Geliş Tarihi: 06.11.2020

Accepted / Kabul Tarihi: 27.01.2021

DOI: 10.35440/hutfd. 822754 


\section{Giriş}

Helikobakter pylori (Hp) asidik mide $\mathrm{pH}^{\prime}$ sında kolonize olabilen gram negatif bir bakteridir. Dünya nüfusunun yarısından fazlasını enfekte eden bu bakteri, gelişmekte olan ülkelerde daha yüksek bir prevalansa sahiptir $(1,2)$. Türkiye'de ise yetişkin nüfusta $\mathrm{Hp}$ prevalansının \% 67,6 - 81,3 olduğu belirtilmektedir (3). Hp'nin bulaşma şekli hala belirsiz olup insandan insana oral-oral veya fekal-oral yolla yayılım en makul görünen bulaşma yollarıdır $(1,2)$. Dünya sağlık örgütü tarafından sınıf 1 kanserojen olarak kabul edilen Hp'nin kronik inflamasyona neden olarak peptik ülser, mide adenokarsinomu ve MALT (mucosa-associated lymphoid-tissue) lenfoma ile yakın ilişkili olduğu bilinmektedir $(4,5)$. Bu nedenle Hp eradikasyon tedavisi önem kazanmakta ve asemptomatik hastalarda bile hastaya tedavi seçeneği sunulması gerektiği belirtilmektedir (6). Ancak antibiyotiklere direnç geliştirebilme yeteneği nedeniyle Hp'nin tedavisi gittikçe zorlaşmaktadır. Tedaviye yanıt oranlarına göre etkinlik 5 grupta sınıflandırılmıştır. Buna göre eradikasyon başarısı \%95-100 olanlar mükemmel; \%90-94 olanlar iyi; \%85-89 olanlar yetersiz; \%81-84 olanlar kötü ve $\leq \% 80$ kabul edilemez olarak belirlenmiştir (7). Tedavide kabul edilebilir başarıyı yakalayabilmek için en az iki farklı antibiyotik, proton pompa inhibitörü (PPI) ve bizmut içeren tedavi rejimleri geliştirilmiştir. Klaritromisin, metronidazol, amoksisilin, tetrasiklin, levofloksasin $\mathrm{Hp}$ eredikasyon tedavisinde en sık kullanılan antibiyotiklerdir. Başlangıçta amoksisilin, klaritromisin ve bir PPI içeren üçlü tedavi rejimi en yaygın kullanılan birinci sıra tedavi rejimiydi. Bu tedavi rejimi ile eradikasyon oranı $\% 85$ 'in üzerindeyken, bazı ülkelerde bu oran zamanla $\% 50$ 'lere kadar düşmüştür $(3,8)$. Bunun sonucunda, concomitant ve ardışık tedavi rejimlerinin kullanımı gündeme gelmiştir. Klaritromisin direncinin arttığı bölgelerde bizmut içeren ve klaritromisin yerine metronidazol kullanılan dörtlü tedavi rejimleri uygulanmaktadır. Yapılan çalışmalarda daha önceden klaritromisin ve metronidazol kullanmış olan hastalarda gelişen antibiyotik direncine bağlı olarak Hp tedavi rejimleriyle eradikasyon oranlarının belirgin düştüğü gösterilmiştir (9).

Bu çalışmamızda, hastanemizde son 4 yılda Hp eradikasyon tedavisinde en sık kullanılan üç tedavi rejiminin etkinliğini araştırdık.

\section{Materyal ve Metod}

Ağustos 2016 ile Ağustos 2020 tarihleri arasında Diyarbakır Sağlık Bilimleri Üniversitesi Gazi Yaşargil Eğitim ve Araştırma Hastanesi Gastroenteroloji Endoskopi Ünitesi'nde dispepsi nedeniyle endoskopi yapılan 12192 hasta retrospektif olarak incelendi. Öncesinde H.pylori tedavisi almayan, gastroskopi esnasında H.pylori için antrumdan en az 2 biyopsi alınıp histopatolojik olarak Hp pozitifliği saptanan ve tedavi verilip tedaviden en az 4 hafta sonra yine antrumdan alınan en az 2 biyopsi ile $\mathrm{Hp}$ eradikasyon durumları belirlenen hastalar çalışmaya dahil edildi. Biyopsiler \%10 formalin solüsyonu içeren kaplarla hastanemiz patoloji bölümüne yollanmış ve Sydney sınıflandırılmasına göre değerlendirilmiştir. On sekiz yaşından küçük hastalar, mide adenokarsinomu saptanan hastalar, uygun dozda eradikasyon tedavisi almayan hastalar ve tedavi sonrası endoskopik biyopsisi olmayan hastalar çaıışma dışı bırakıldı. Çalışmaya dahil edilen hastalar aldıkları tedavi rejimine göre gruplandırıldı. Grup 1: Lansoprazol, klaritromisin, amoksisilin; grup 2: Lansoprazol, bizmut subsalisilat, klaritromisin, amoksisilin; grup 3: Lansoprazol, bizmut subsalisilat, metronidazol, tetrasiklin alan hastalar olarak belirlendi. Bu gruplara başlanmış olan tedavi rejimlerinin detayları Tablo 1'de verilmiştir.

Çalışmamız Diyarbakır SBÜ Gazi Yaşargil Eğitim ve Araştırma Hastanesi Etik Kurulu tarafından 11.09.2020 tarihinde onaylandı (Etik Kurul No: 556 ) ve çalışmanın bütünü Helsinki Deklarasyonu yönergelerine uygun şekilde gerçekleştirildi.

\section{istatiksel analiz}

Veri analizi Statistical Package for the Social Sciences (SPSS) 16.0 bilgisayar paket programı ile yapıldı. Tanımlayıc istatistikte sayısal veriler ortalama \pm standart sapma ile, oransal veriler ise sayı ve yüzde oranları olarak verildi. İstatistiksel analizlerde anova testi ve ki-kare testleri kullanıldı. $P<0.05$ değerleri istatistiksel olarak anlamlı kabul edildi.

\section{Bulgular}

Çalışmaya alınan 60 vakanın 29'u (\%48.3) kadın, 31'i (\%51.7) erkek olup yaş ortalaması $42.88 \pm 15.17$ yıl (18-85) idi. Iki gastroskopik işlem arasında geçen ortanca süre 11.9 (1-34) ay idi. İlk endoskopik işlemde en sık tanı \%70 ile eritematöz gastrit olup diğerleri sırasıyla mide ve/veya bulbus ülseri (\%8.3), mide polibi (\%8.3), hiatal herni / özofajit (\%5), eritematöz gastrit + bulbit (\%3.3), ektopik pankreatit (\%1), nörendokrin tümör (\%1), MALT lenfoma (\%1) olarak saptandı. Tüm endoskopik tanılar Tablo 2'de verilmiştir. On altı (\%27.1) hastada histopatolojik olarak intestinal metaplazi saptandı.

Tablo 1. Hp tedavisinde uygulanan tedavi rejimleri

\begin{tabular}{|c|c|c|}
\hline & Tedavi rejimi & Tedavi süresi \\
\hline & Lansoprazol $30 \mathrm{mg} 2 \times 1$ & \\
\hline Grup 1 (klasik üçlü tedavi) & $\begin{array}{l}\text { Klaritromisin } 500 \text { mg 2x1 } \\
\text { Amoksisilin } 1 \text { gr 2x1 }\end{array}$ & 14 gün \\
\hline $\begin{array}{l}\text { Grup } 2 \text { (bizmut eklenmiş } \\
\text { klasik üçlü tedavi) }\end{array}$ & $\begin{array}{l}\text { Bizmut subsalisilat } 262 \mathrm{mg} \\
\qquad 4 \times 1 \\
\text { Lansoprazol } 30 \mathrm{mg} 2 \times 1 \\
\text { Klaritromisin } 500 \mathrm{mg} 2 \times 1 \\
\text { Amoksisilin } 1 \mathrm{gr} 2 \times 1\end{array}$ & 14 gün \\
\hline $\begin{array}{l}\text { Grup } 3 \text { (bizmutlu dörtlü te- } \\
\text { davi) }\end{array}$ & $\begin{array}{l}\text { Bizmut subsalisilat } 262 \mathrm{mg} \\
\qquad 4 \times 1 \\
\text { Lansoprazol } 30 \mathrm{mg} 2 \times 1 \\
\text { Tetrasiklin } 5004 \times 1 \\
\text { Metronidazol } 500 \mathrm{mg} 3 \times 1\end{array}$ & 14 gün \\
\hline
\end{tabular}

Eradikasyon tedavisi başlanan 20 (\%33.3) hasta grup 1'de, 23 (\%38.3) hasta grup 2'de, 17 (\%28.3) hasta grup 3'te idi. Grup 1,2 ve 3'ün yaş ortalamaları sırasıyla 40.05 \pm 15.33 , 
42.86 $\pm 15.90,46.23 \pm 14.14$ ve kadın/erkek oranları sırasıyla 11/9, 9/14, 9/8 idi. Bu gruplar arasında yaş ortalamaları $(p=0.474)$ ve cinsiyet $(p=0.577)$ açısından anlamlı farklılık yoktu. Otuz dört (\%57.6) vakada tedavi sonrası yapılan endoskopik biyopside Hp negatifleşmişti. Grup 1,2 ve 3'ün tedavi sonrası $\mathrm{Hp}$ negatifleşen hasta sayı ve oranları sırası ile 10 (\%50), 12 (\%52.2) ve 12 (\%66.7) olup gruplar arasında istatistiksel olarak anlamlı farklılık saptanmadı $(p=0.236)$ (Tablo 3).

Tablo 2. Hp (+) hastaların endoskopik tanıları

\begin{tabular}{lc}
\hline Endoskopik tanılar & Hasta sayısı (\%) \\
\hline Eritematöz gastrit & $42(\% 70)$ \\
Eritematöz gastrit ve bulbit & $2(\% 3,3)$ \\
Mide ve/veya bulbus ülseri & $5(\% 8,3)$ \\
Mide polipi & $5(\% 8,3)$ \\
Hiatal herni / özofajit & $3(\% 5)$ \\
Ektopik pankreatit & $1(\% 1,7)$ \\
Nöroendokrin tümör & $1(\% 1,7)$ \\
MALT Lenfoma & $1(\% 1,7)$ \\
\hline
\end{tabular}

Tablo 3. Üç tedavi rejiminin karşılaştırılması

\begin{tabular}{ccccc}
\hline & Grup 1 & Grup 2 & Grup 3 & P \\
& $(\mathrm{n}=20)$ & $(\mathrm{n}=23)$ & $(\mathrm{n}=17)$ & \\
\hline Yaş, yıl & $40.05 \pm 15.33$ & $42.86 \pm 15.90$ & $46.23 \pm 14.14$ & 0,474 \\
Cinsiyet (K/E) & $11 / 9$ & $9 / 14$ & $9 / 8$ & 0,527 \\
Eradikasyon & $\% 50$ & $\% 52,2$ & $\% 66,7$ & 0,236 \\
oranı (\%) & & & & \\
\hline
\end{tabular}

\section{Tartışma}

Bu çalışmada, hastanemizde ve Türkiye'de en sık kullanılan üç $\mathrm{Hp}$ eradikasyon tedavi rejiminin etkinliğini değerlendirdik. Klasik üçlü tedavi, bizmut eklenmiş klasik üçlü tedavi ve bizmutlu dörtlü tedavi rejimlerinin eradikasyon oranlarını sırası ile $\% 50, \% 52.2$ ve $\% 66.7$ olarak saptadık. Global bir sağlık sorunu haline gelen ve özellikle gelişmekte olan ülkelerde yüksek antibiyotik direnci nedeniyle $\mathrm{Hp}$ enfeksiyonu can sıkıcı bir hale gelmiştir. Hp eradikasyon tedavisinin başarısını etkileyen faktörlerin başında antibiyotik direnci, bireysel, çevresel ve genetik faktörler yer alır $(10,11)$. Hp tedavisinde konsensus oluşturmak için en son 2017'de Amerika Gastroenteroloji Koleji (ACG) kılavuzu ve Maastricht $\mathrm{V}$ konsensus raporu açıklanmıştır $(7,12)$. Türkiye'de ise Hp tedavisine yönelik henüz bir görüş birliği oluşturulmamıştır. ACG kılavuzu Hp pozitif saptanan tüm hastaların tedavi edilmesini önermektedir. Maastricht $\mathrm{V}$ konsensus raporunda klaritromisin ve metronidazol direncine göre eradikasyon tedavisinin belirlenmesi önerilmektedir. Klaritromisin ve metronidazol direnci \%15'in üzerinde olan bölgelerde bizmut içeren dörtlü tedavi (PPI + iki antibiyotik +bizmut) veya bizmutsuz dörtlü (PPI, klaritromisin, amoksisilin ve nitroimidazol) önerilmektedir (12). Yapılan bir çalışmada Türkiye'de klaritromisin ve metronidazol direnci \%40 olarak belirtilse de (13), başka bir çalışmada klaritromisin direncinin \%50'nin üzerinde olduğu ve metronidazol direncinin ise \%49 olduğu belirtilmektedir $(14,15)$.

Birinci sıra Hp eradikasyon tedavisinde klasik üçlü tedavinin etkinliğini sistematik olarak analiz eden bir çalışmada, bu tedavi rejiminin başarı oranı $\% 68,8$ olarak bildirilmiş ve tedavi başarısının yıllar geçtikçe azaldığı belirtilmiştir (16). iki bin dört yılında yapılan bir çalışmada, klasik üçlü tedavi ve bizmut eklenmiş klasik üçlü tedavi ile Hp eradikasyon oranları sırası ile \%56 ve \%68 olarak saptanmıştır (17). Yakın zamanda yayınlanan bir çalışmada klasik üçlü tedavi ile Hp eradikasyon oranı \%56.7 ve bizmut eklenmiş klasik üçlü tedavi ile eradikasyon oranı \%53.3 olarak saptanmıştır (18). Bizim çalışmamızda ise klasik üçlü tedavinin eradikasyon oranını \%50, bizmut eklenmiş klasik üçlü tedavi rejiminin eradikasyon oranını ise $\% 52.2$ olarak bulduk. Bu oranların bu kadar düşük olmasının nedeni yüksek klaritromisin direnci ile açıklanabilir (19). Bu iki tedavi rejiminin tedavi başarısı, hedeflenen eradikasyon oranın çok altında olup $\mathrm{Hp}$ eradikasyon tedavisinde kullanılmaması uygun olacaktır.

Klasik üçlü tedavi ve bizmut eklenmiş klasik üçlü tedavinin Hp eradikasyon başarısının düşük olması nedeniyle dörtlü, ardışık ve concomitant tedavi rejimleri geliştirilmiştir. Ülkemizde de sık kullanılan dörtlü tedavi rejimi bizmut, PPI, metronidazol ve tetrasiklin içeren dörtlü tedavi rejimidir. Klasik üçlü tedaviye yanıt vermeyen, endoskopik biyopsi ile Hp varlığı ve tedavi yanıtının değerlendirildiği bir çalışmada, 14 günlük dörtlü tedavi rejimi (lansoprazol, ranitidin bizmut sitrat, tetrasiklin ve metronizol) ile $\mathrm{Hp}$ eradikasyon oranı \%67.7 olarak saptanmıştır (20). Özden ve arkadaşlarının 2010 yılında yayınladıkları ve 10 yıl boyunca kendi hastalarına uyguladıkları tedavi rejimlerini karşılaştırdıkları bir çalışmada, iki haftalık kolloid bizmut sitrat, tetrasiklin ve metronidazol içeren tedavi rejimiyle Hp eradikasyon oranını \%92.3 olarak saptamışlardır. Bu çalışmanın sonunda Özden ve arkadaşları, Türkiye gibi klaritromisin direncinin yüksek olduğu ülkelerde, bizmut subsitratlı üçlü tedavi veya tetrasiklin, amoksisilin, metronidazol ve PPI içeren dörtlü tedavi rejimini önerdiklerini belirtmişlerdir (3). Bizmut subsalisilat, tetrasiklin, metronidazol ve PPI'dan oluşan dörtlü tedavinin 10 gün uygulandığı başka bir çalışmada Hp eradikasyon oranı \%83.3 olarak bulunmuştur (21). Bizim çalışmamızda bizmutlu dörtlü tedavi ile Hp eradikasyon oranını \%66.7 olarak bulduk. Bizim bulduğumuz oran, $\mathrm{Hp}$ eradikasyon tedavisi için kabul edilebilir oran olan \%80'in altındadır. Bulduğumuz eradikasyon oranının diğer çalışmalardan düşük olmasının nedeni; çalışmamızın bu çalışmalardan daha sonra yapılmış olması ve/veya metronidazol direnç oranının bizim hastalarımızda daha fazla olmasına bağlı olabilir.

Çalışmamızdaki sınırlayıcı faktörler; retrospektif olması, çalışmaya alınan hasta sayısının az olması, Hp varlığının tek tanı testi ile yapılmış olması, kontrol biyopsilerin aynı sürede bakılmamış olmasıdır.

Sonuç olarak; son dört yılda Hp eradikasyon tedavisinde kullanılan üç farklı tedavi rejiminin başarı oranlarını araştırdık. Üç tedavi rejiminin de başarı oranını kabul edilebilir oranın çok altında saptadık. Türkiye'de, klasik üçlü tedavi ve bizmut eklenmiş klasik üçlü tedavinin Hp eradikasyon tedavisinde kullanılmaması daha uygun olabilir. Yüksek metronidazol direnci nedeniyle, bizmutlu dörtlü tedavinin 
kullanılması da uygun olmayabilir. Bu üç tedavi rejiminin etkinliğinin değerlendirilmesi için, geniş ölçekli çalışmalara ihtiyaç vardır. Ayrıca ülkemizde antibiyotik direnç çaIışmaları yapılarak, Hp eradikasyon tedavisinde yeni tedavi rejimlerinin geliştirilmesi uygun olabilir.

Etik onam: Bu çalışma için Diyarbakır SBÜ Gazi Yaşargil Eğitim ve Araştırma Hastanesi Etik Kurulu tarafından 11.09.2020 tarihinde etik onam alındı (Etik Kurul Karar No: 556 ).

\section{Yazar Katkıları:}

Konsept: N.E.

Literatür Tarama: N.E.; B.E.

Tasarım: B.E.; F.B.

Veri toplama: N.E.; B.E.; F.B.

Veri analizi ve yorumlama: N.E.; B.E.

Makale yazımı: N.E.; B.E.; F.B.

içeriğin eleştirel incelenmesi: N.E.; F.B.

Çıkar Çatışması: Yazarlar çıkar çatışması olmadığını bildirmişlerdir.

Finansal Destek: Bu çalışma herhangi bir fon tarafından desteklenmemiştir.

\section{Kaynaklar}

1. Goh KL, Chan WK, Shiota S, Yamaoka Y. Epidemiology of Helicobacter pylori Infection and Public Health Implications. Helicobacter 2011;16 Suppl 1(01):1-9.

2. Eusebi LH, Zagari RM, Bazzoli F. Epidemiology of Helicobacter pylori Infection. Helicobacter 2014;19 Suppl 1:1-5.

3. Özden A, Seven G, Bektaş M. Effectiveness of different treatment regimens in helicobacter pylori eradication: Tenyear experience of a single institution. Turk J Gastroenterol 2010;21(3):218-23.

4. Schistosomes, liver flukes and Helicobacter pylori. IARC Working Group on the Evaluation of Carcinogenic Risks to Humans. IARC Monogr Eval Carcinog Risks Hum 1994;61:1241.

5. Makola D, Peura DA, Crowe SE. Helicobacter pylori infection and related gastrointestinal diseases. J Clin Gastroenterol 2007;41(6):548-58.

6. Chey WD, Leontiadis GI, Howden CW, Moss SF. ACG Clinical Guideline: Treatment of Helicobacter pylori Infection. Am J Gastroenterol 2017;112(2):212-38.

7. Graham DY, Lu H, Yamaoka Y. A report card to grade Helicobacter pylori therapy. Helicobacter. 2007;12(4):275-8.

8. Gumurdulu Y, Serin E, Özer B, Kayaselcuk F, Ozsahin K, Cosar AM, et al. Low eradication rate of Helicobacter pylori with triple 7-14 days and quadriple therapy in Turkey. World J Gastroenterol 2004;10(5):668-71.

9. Diaconu S, Predescu A, Moldoveanu A, Pop CS, Fierbințeanu-Braticevici $C$. Helicobacter pylori infection: old and new. J Med Life 2017;10(2):112-7.

10. Yilmaz B, Koseoglu H, Coskun Y, Deveci M, Kekilli M. Comparison between different first-line therapy protocols in eradicating Helicobacter pylori in a region with high clarithromycin resistance.Prz Gastroenterol 2018;13(2):1506.

11. Zhang W, Chen Q, Liang X, Liu W, Xiao S, Graham D, et al. Bismuth, lansoprazole, amoxicillin and metronidazole or clarithromycin as first-line Helicobacter pylori therapy. Gut 2015;64(11):1715-20.

12. Malfertheiner P, Megraud F, O'Morain C, Gisbert JP,
Kuipers EJ, Axon AT, et al. Management of helicobacter pylori infection-the Maastricht V/Florence consensus report. Gut 2017;66(1):6-30.

13. Thung I, Aramin H, Vavinskaya V, Gupta S, Park JY, Crowe $\mathrm{SE}$, et al. Review article: The global emergence of Helicobacter pylori antibiotic resistance. Aliment Pharmacol Ther 2016;43(4):514-33.

14. Bağlan PH, Bozdayı G, Özkan M, Özden A. Klaritromisin dirençli Helicobacter pylori'nin saptanmasında, E-Test ve Agar Dilüsyon metodlarının karşılaştırılması. Akademik Gastroenteroloji Dergisi 2005;4(2):83-7.

15. Kantarçeken B, Yıldırım B, Karıncaoğlu M, Aladağ M, Hilmioğlu F. Helicobacter pylori and antibiotic resistance. Turk J Gastroenterol 2000;11(2):141-145.

16. Kadayifci A, Buyukhatipoglu $H$, Cemil Savas $M$, Simsek I. Eradication of Helicobacter pylori with triple therapy: An epidemiologic analysis of trends in Turkey over 10 years. Clin Ther 2006:1960-6.

17. Özer B, Serin E, Coşar AM, Kayaselçuk F, Gür G, Yılmaz U, et al. Helicobacter pylori eradikasyon tedavisinde lansoprozol, klaritromisin ve amoksisilin ile ranitidin bizmut sitrat, lansoprozol, klaritromisin ve amoksisilin rejimlerinin etkinliğinin karşılaştırılması etkinliğinin karşılaştırılması. Akademik Gastroenteroloji Dergisi 2004;3(3):125-8.

18. Sert U, Cindoğlu Ç, Uyanıkoğlu A. Helikobakter pilori eradikasyonunda klasik üçlü tedavi İle klasik üçlü+bizmut tedavisinin karşılaştırılması. Harran Üniversitesi Tıp Fakültesi Dergisi 2019;16(3):484-7.

19. Sezgin O, Aydın MK, Özdemir AA, Kanık AE. Standard triple therapy in Helicobacter pylori eradication in Turkey: Systematic evaluation and meta-analysis of 10-year studies. Turk J Gastroenterol. 2019;30(5):420-35.

20. Aydemir $S$, Bayraktaroğlu T, Üstündağ $Y$, Borazan A, Sekitmez N, Aktunç E, et al. Standart üçlü tedavi ile eradikasyon sağlanamayan Helicobacter pylori enfeksiyonunda lansoprazol, ranitidin bizmut sitrat, tetrasiklin ve metronidazolden oluşan dörtlü tedavinin etkinliği. Akademik Gastroenteroloji Dergisi 2004;3(3):129-33.

21. Bozkurt $H$, Sert OZ, Kaplan E, Aray E, Olmez T, Uzun O, et al. Comparsion of first-line eradication therapy protocols for Helicobacter pylori in regions with clarithromycin resistance. Annals of Medical Research 2019;26(7):1227-34 